\title{
EFICÁCIA E TOLERANCIA DO NITROFURFURIIDENE (1) NA FASE CRÔNICA DA MOLÉSTIA DE CHAGAS
}

\author{
Newton Neves da Silva **, Gisebel Kuhn **, João Francisco Cardoso dos Santos *** \\ Günther Von Eye ${ }^{* * *}$ e João Aioisio Braga Chaher *****
}

Foram selecionados 25 pacientes chagásicos crônicos que apresentavam sorologia positiva e elevada parasitemia.

$A 15$ deles, durante 120 dias, foi ministrado o Nitrofurfurilidene na dose diária de 8 a $10 \mathrm{mg}$ por quilo de peso. Aos 10 restantes deu-se placebo. No trans $e$ pós-tratamento não se verificaram alterações nas funções hepática, hematopoiética ou renal de caráter iatrogênico. Xenodiagnóstico e provas sorológicas foram realizadas mensalmente. O xenodiagnóstico, nos 15 doentes tratados, aos $60^{\circ}$ dias da fase trans-terapêtica, mostrou-se negativo e assim se manteve durante 4 anos, periodo de tempo que durou a nossa observaçấo. Quanto às reações sorodiagnósticas o mesmo não ocorreu, embora a partir dos 12 meses do término do tratamento o grupo que recebeu a droga tenha passado a apresentar niveis mais baixos de anticorpos.

Os A.A. comentam o desacordo entre os achados do xenodiagnóstico $e$ os das provas sorológicas e sugerem uma hipótese para justificá-lo. Concluem que, embora com menos evidência do que nas formas agudas, o Nitrofurfurilidene revela certa eficácia na fase crônica da infecção chagásica.

\section{INTRODUÇÃO}

Até agora restrita à América Latina, onde, segundo Rassi \& Ferreira (15), existem sete milhōes de pessoas infectadas, a Moléstia de Chagas tem vários aspectos à espera de so:u-ão, a começar pelo tratamento específico.

Dentre as substâncias ensaiadas, tanto na infecção humana como na doença animal experimental, os nitrofuranos foram aquelas que mais esperanças trouxeram aos pesquisadores e, por isso, neles foram concentrados os maiores esforços no sen- tido de resolver o importante problema da terapêutica específica dessa tripanosomiase.

O grupo dos nitrofuranos compreende substâncias dotadas de variada atividade antimicrobiana, algumas com acentuada ação tripanosomicida. Um histórico da evolução dos estudos referentes a essas drogas frente ao Trypanosoma cruzi encontra-se nos trabalhos de Coura \& Rodrigues da Silva (10), Marra (13) e Brener (4).

Rock et alii (1) numa série de experimentos mostraram que o Nitrofurfurilidene age "in vivo" contra as formas tripomas-

* Trabalho realizado no Instituto de Pesquisas Biológicas da Secretaria da Saúde, no Departamento de Parasitologia e Microbiologia do Instituto de Biocências da U.F.R.G.S. e no Hospital Psiquiátrico Sáo Pedro de Porto Alegre.

* D) Instituto de Pesquisas Bi lógicas do Rio Grande do Sul

*** Dó Departamento de Parasitologia e Microblologia do Instituto de Blociências da U.F.R.G.S.

**** Do Hospital Psiquiátrico São Pedro de Porto Alegre.

**** Do Instituto Nacional de Previdência Nacional.

(1) O NTTROFURFURILIDFNE, designado provisoriamente Bay 2502, fol sintetizado por HERLINGER, MEYER G PETERSON, pesquisadores da Farbenfabriken Bayer AG, Alemanha Ocidental. 
tigotas e amastigotas do Trypanosoma cruzi.

Com base nos trabalhos de Ferreira et alii (11), Cerisola et alii (7), Tourres (18) e Rassi \& Ferreira (15), essa droga administrada a pacientes de forma aguda, mostrou resultados altamente favoráveis.

No que se refere à fase crônica da infeç̧ão chagásica, os trabalhos publicados ainda não permitem uma tomada de posição. Em que pesem as naturais dificuldades que seriam encontradas, programamos este estudo com o objetivo de avaliar a eficácia e tolerância do Nitrofurfurilidene nessa fase da infecção chagásica.

\section{MATERIAL E MÉTODOS}

\section{1 - Tipo de paciente}

No Hospital Psiquiátrico São Pedro de Porto Alegre, Brasil, foram selecionados 25 doentes mentais crônicos, com idade compreendida entre 23 e 52 anos, do sexo masculino, que apresentavam as reaçōes de fixação de complemento, hemoaglutinação e imunofluorescência simultaneamente positivas, além de parasitemia elevada e persistente detectada pelo xenodiagnóstico.

o exame clínico não revelou outra patologia evidente além da doença mental. Todos estavam assintomáticos com relação à Moléstia de Chagas e internados há mais de 4 anos. Visto que no local não há triatomíneos, consideramos tais pacientes como chagásicos crônicos. Durante todo o período do nosso estudo permaneceram internados no hospital, afastando, assim, a possibilidade de reinfeç̧ão.

\section{2 - Exames de controle}

Afora o clínico. foi realizado o eletrocardiográfico como também, antes, durante e depois do tratamento, os seguintes testes laboratoriais: hemograma, prova de função hepática (bilirrubina, transaminases, Hanger e timol), hemossedimentação e exame comum de urina, os quais na fase trans-terapêtica foram efetuados mensalmente.

A pesagem dos doentes foi feita a cada 15 dias até o término do tratamento e, a seguir, mensalmente.

\section{3 - Sorologia}

As amostras de sangue foram coletadas mensalmente com os pacientes em jejum. O próprio tubo de coleta foi centrifugado e o soro dividido em 2 porções de $1 \mathrm{ml}$. Os soros foram liofilizados em aparelho Repp e mantidos em atmosfera de nitrogên o. Depois de fechados com tampa de alumínio e rotulados, os frascos foram conservados no freezer a $-20^{\circ} \mathrm{C}$.

Um frasco de cada amostra foi enviado para o Instituto "Mário Fatalla Chaben", de Buenos Aires, e outro examinado em Porto Alegre. As provas sorológicas foram feitas com o mesmo antígeno e pelo mesmo técnico ao fim do nosso estudo, com excecão das amostras de sangue coletadas após 4 anos do início do tratamento, cujos exames foram realizados só em Porto Alegre e, evidentemente, com outra partida de antigeno.

A Reação de fixação do complemento foi realizada somente quando da seleção dos pacientes e o foi, conforme a técnica descrita por Cerisola \& Rosenbaum (9) .

A Reação de hemoaglutinação foi praticada, conforme a técnica de Boyden (2) e modificações propostas por Cerisola \& Lazzari (8) sendo cada amostra de soro testada nas diluiōes de 1:2 até 1:128.

A Reação de imunofluorescência foi executada conforme a técnica recomendada por Camargo (5) e cada soro fol examinado nos títulos de $1: 15$ até $1: 128$.

A Reação de imunofluorescência foi executada conforme a técnica recomendada por Camargo (5) e cada soro foi examinado nos títulos de $1: 15$ até $1: 960$.

\section{4 - Xenodiagnóstico}

Na prova xenodiagnóstica adotamos um critério técnico que nos permitisse, além de determinar a positividade ou negatividade, ter uma avaliação semi-quantitativa. Para cada paciente foram utilizados 88 Triatoma infestans, contidos em 8 caixas, rotuladas de $A$ a $H$, cada uma contendo 11 ninfas de $3^{\circ}$ ou $4^{\circ}$ estádio. Quatro caixas foram colocadas na face externa de cada braço durante 30 minutos. As caixas $A, B, C$ e $D$ foram examinadas em Porto Alegre e as E, F, G, e $\mathrm{H}$ o foram em Bue- 
nos Aires, após 30, 60 e 90 dias da data de aplicação e dentro da seguinte orientação:

a) Exonerava-se o conteúdo de cada caixa em um copo, no qual eram contados os triatomíneos, anotado o número de mortos (se houvesse) e desprezadas as capas resultantes de ecdíses

b) Em uma placa de porcelana escavada realizavam-se dois "pools" das fezes com salina tamponada ( $\mathrm{pH}$ 7,2 ),- cada um oriundo da metade do número de insetos existentes na caixa.

c) De cada "pool" preparavam-se 2 lâminas, as quais eram examinadas por 2 técnicos distintos. Os casos positivos sempre foram confirmados por mais de 1 técnico. Em Porto Alegre as caixas positivas não eram mais examinadas.

\section{5 - Tratamento}

Usamos em nosso estudo, Nitrofurfurilidene em comprimidos sulcados de $120 \mathrm{mg}$. O placebo, com a mesma cor da droga, era um pouco menor. Os pacientes foram divididos em 2 grupos: Um, de 10 doentes, recebeu o placebo e outro, de 15 pacientes, recebeu a droga.

A dose diária foi de 8 a $10 \mathrm{mg}$ por quilo de peso, em 3 porções ao dia. Incumbimos para tal enfermeiros altamente responsáveis para oue tivéssemos certeza de que a droga fosse ministrada na forma correta $e$ precisa. O ajuste da dose em relação ao peso do paciente foi feito quinzenalmente.

A droga foi ministrada durante 120 dias. Esse tratamento prolongado deriva dos trabalhos de Brener (4) que observou que na infecção experimental do camundongo devem ser mantidos níveis elevados, no mínimo, por 60 dias. O prazo de 120 dias foi puramente arbitrário, na presunção de que as formas amastigotas, nesse periodo, evoluam atě as formas tripomastigotas, quando seriam mais suscetíveis ao agente tripanosomicida.

\section{RESULTADOS}

\section{1 - Xenodiagnóstico}

O xenodiagnóstico praticado dentro do critério técnico atrás descrito mostrou-se de grande valia na evicienciação do Trypanosoma cruzi. Quando da fase de seleção dos pacientes, Lima et alii (12) em um grupo de 50 indivíduos que apresentavam positividade para as 3 reaçóes sorológicas já referidas, obtiveram com a leitura de 30 dias $56 \%$ de positivos, valor aumentado para $58 \%$ com a de 60 dias.

Mantendo-sa essa metodologia, realizamos em nossos doentes 513 exames utilizando um total de 45.056 triatomíneos. Foram efetuados 4 xenodiagnósticos préterapêutico, 4 trans-terapêutico e 18 pós-terapêutico.

o quadro 2 mostra os resultados. Nele se nota que o grupo placebo mante.ve-se positivo durante uma observação de 27 meses enquanto que, o grupo teste, a partir do primeiro mês (com uma exceção) negativou e assim permaneceu até a última leitura, isto é, até 49 meses após o inicio do tratamento.

\section{2 - Sorologia}

Im estudo estatístico dos nossos resultados permitiu a confecção das figuras 2 e 3, nas quais temos a curva sorológica do grupo placebo e do grupo teste, na figura 2 com a imunofluoressência e na 3, com a hemoaglutinação. Ele revela que, dentro dos critérios convencionais, a totalidade dos soros ainda se mostra reagente, embora apresentem flutuações de título através do tempo.

Nota-se que, em torno dos 12 meses do término do tratamento, o grupo que recebeu a droga passa a apresentar niveis mais baixos de anticorpos, os quais são mantidos até a última determinação, quando o título dos imunofluorescentes oscilou entre $1 / 30$ a $1 / 120$ enquanto os hemoaglutinantes de $1 / 16$ a $1 / 128$.

\section{3 - Efeitos colaterais}

Cumpre-nos frisar que os 15 pacientes tratados eram também portadores de doença mental crônica e a isso se deve atribuir o fato de que os sintomas e sinais subjetivos, descritos por outros autores tenham sido anotados tão poucas vezes.

O quadro no 1 reflete a colateralidade registrada. Nele, como também no gráfico da figura 1, cbserva-se que todos os pacientes perdem peso, em média $12,8 \%$, em- 
QUADRO 1

EFEITOS COLTERAIS COM O NITROFUFURILIDENE NO TRATAMENTO DA DOENÇA DE CHAGAS

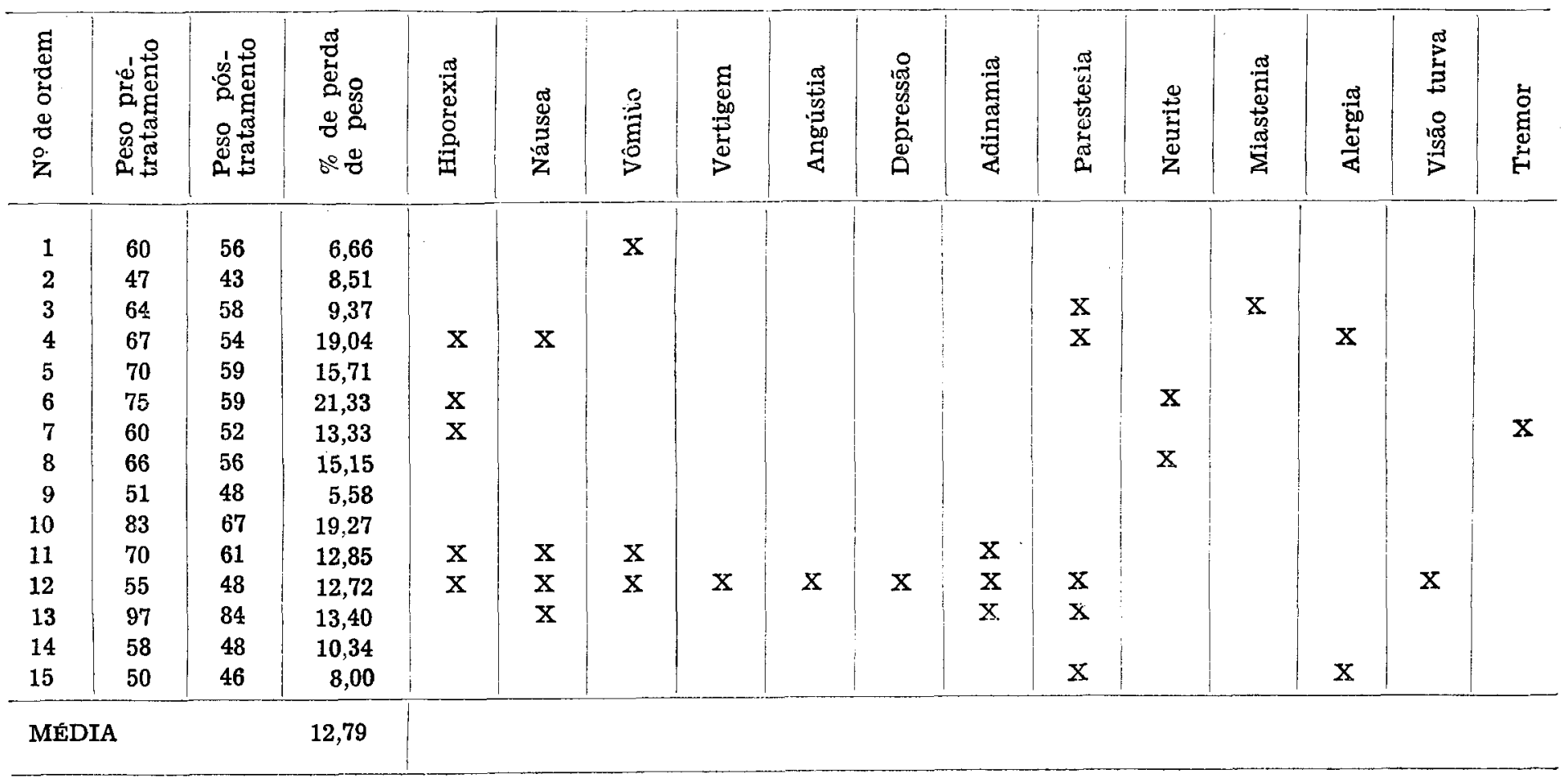



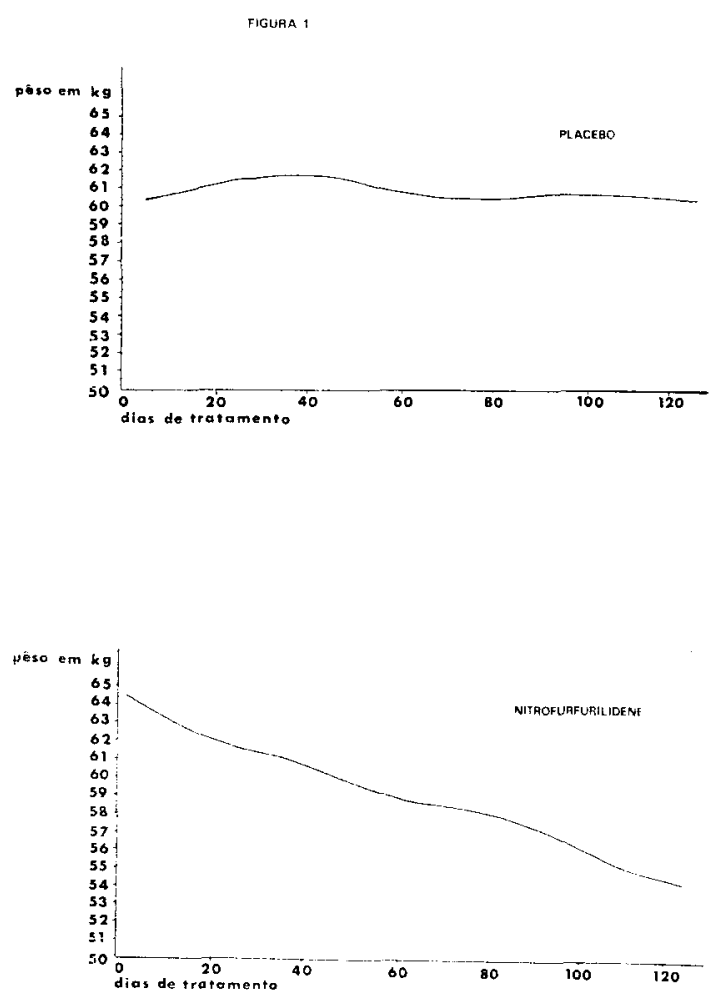

FIGURA 1 - Curva ponderal des dois grupos estudacoos.

bora só um terço tenha apresentado hiporexia. Seis meses após o término do tratamento, todos, com exceção de dois, tinham recuperado o seu peso inicial. Em um dos dois foi verificado, um ano após o encerramento da terapia, ser portador de uma tuberculose pulmonar.

A má tolerância digestiva (náuseas e/ou vómitos) foi anotada em 5 casos.

Entre as alterações neurológicas registramos:

- Vertigens, visão turva, neurite e tremor em um caso; adinamia geral em dois casos; miastenia localizada nas pernas em quatro casos e parestesia em cinco casos. Nestes últimos pacientes o tratamento foi suspenso no dia $94^{\circ}$ e reiniciado no dia $106^{\circ}$, com os sintomas desaparecidos.

Não observamos convulsões, embora houvesse no grupo 3 pacientes com passado comicial.
Essas alterações para o lado do sistema nervoso se manifestaram após 3 meses de tratamento. Um paciente apresentou no $56^{\circ}$ dia de tratamento uma dermatite alérgica - eritrodermia exfoliativa - com severa repercussão sobre o estado geral, obrigando-nos a suspender o tratamento. Após 3 meses recuperou-se plenamente.

\section{4 - Anatomopatologia}

Os pacientes, em número de 4 , que faleceram no decurso de nosso estudo foram necropsiados não tendo sido encontradas lesões que pudessem ser imputadas à medicação. O exame microscópico não revelou focos de formas amastigotas.

\section{5 - Exames de controle}

A prova eletrocardiográfica realizada em todos os pacientes revelou em apenas um alteraçōes compatíveis com miocardite 


\begin{tabular}{|c|c|c|c|c|c|c|c|c|c|c|c|c|c|c|c|c|c|c|c|c|c|c|c|c|}
\hline & \multirow[b]{2}{*}{ NOME } & \multicolumn{4}{|c|}{ PRÉ-TRATAMENTO } & \multicolumn{4}{|c|}{ TRANS-TRATAMENTO } & \multicolumn{13}{|c|}{ POST-TRATAMENTO } & \multirow{2}{*}{\multicolumn{2}{|c|}{$\begin{array}{r}1 \% 6 \\
74 \\
\end{array}$}} \\
\hline & & $\begin{array}{c}3 / 12 \\
69\end{array}$ & $\begin{array}{l}4 / 2 \\
70\end{array}$ & $\begin{array}{l}20 / 3 \\
70\end{array}$ & $\begin{array}{c}19 / 4 \\
70\end{array}$ & $\begin{array}{l}19 / 6 \\
70\end{array}$ & $\begin{array}{c}20 \mid 7 \\
70 \\
\end{array}$ & $\begin{array}{c}20 / 8 \\
70 \\
\end{array}$ & $\begin{array}{c}22 / 9 \\
70\end{array}$ & $\begin{array}{c}21 / 12 \\
70\end{array}$ & $\begin{array}{l}20 \mid 1 \\
71\end{array}$ & $\begin{array}{l}20 / 2 \\
71\end{array}$ & $\begin{array}{c}24 / 5 \\
71\end{array}$ & $\begin{array}{c}24 / 6 \\
71 \\
\end{array}$ & $\begin{array}{c}20 / 7 \\
71\end{array}$ & $\begin{array}{c}23 / 8 \\
71\end{array}$ & $\begin{array}{c}23 / 9 \\
71\end{array}$ & $\begin{array}{c}23 / 10 \\
71 \\
\end{array}$ & $\begin{array}{c}25 / 11 \\
71 \\
\end{array}$ & $\begin{array}{c}27 / 12 \\
71\end{array}$ & $\begin{array}{c}24 / 1 \\
72\end{array}$ & $\begin{array}{c}24 k \\
72\end{array}$ & & \\
\hline 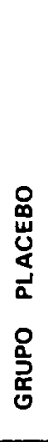 & $\begin{array}{l}\text { A.R. } \\
\text { A.F.R. } \\
\text { A.S.P. } \\
\text { N.A. } \\
\text { W. N. } \\
\text { O. L.V. } \\
\text { S.M. } \\
\text { B.O. } \\
\text { G.F. } \\
\text { P. M. }\end{array}$ & $\begin{array}{l}+ \\
+ \\
+ \\
+ \\
+ \\
+ \\
+ \\
+ \\
+ \\
+\end{array}$ & $\begin{array}{l}+ \\
+ \\
+ \\
+ \\
+ \\
+ \\
- \\
+ \\
- \\
+\end{array}$ & $\begin{array}{l}+ \\
+ \\
+ \\
+ \\
+ \\
- \\
- \\
+ \\
+ \\
+\end{array}$ & $\begin{array}{l}- \\
+ \\
- \\
+ \\
+ \\
+ \\
+ \\
+ \\
- \\
+\end{array}$ & $\begin{array}{l}+ \\
+ \\
- \\
+ \\
- \\
+ \\
+ \\
+ \\
+ \\
+\end{array}$ & $\begin{array}{l}+ \\
+ \\
+ \\
+ \\
+ \\
+ \\
+ \\
+ \\
+ \\
+\end{array}$ & $\begin{array}{l}+ \\
+ \\
- \\
+ \\
+ \\
+ \\
+ \\
+ \\
+ \\
+\end{array}$ & $\begin{array}{l}+ \\
+ \\
- \\
+ \\
+ \\
+ \\
+ \\
+ \\
-\end{array}$ & $\begin{array}{l}+ \\
+ \\
+ \\
+ \\
\text { FAL } \\
+ \\
+ \\
+ \\
+ \\
+\end{array}$ & $\begin{array}{l}+ \\
+ \\
- \\
+ \\
\text { CEU } \\
+ \\
+ \\
+ \\
+ \\
+\end{array}$ & $\begin{array}{c}- \\
+ \\
- \\
+ \\
4 / 10 / 20 \\
+ \\
- \\
+ \\
+ \\
-\end{array}$ & $\begin{array}{l}+ \\
+ \\
+ \\
+ \\
+ \\
- \\
+ \\
- \\
+\end{array}$ & $\begin{array}{l}+ \\
+ \\
+ \\
+ \\
+ \\
+ \\
+ \\
+ \\
+\end{array}$ & $\begin{array}{l}+ \\
+ \\
+ \\
+ \\
+ \\
+ \\
+ \\
+ \\
+\end{array}$ & $\begin{array}{l}+ \\
+ \\
+ \\
+ \\
+ \\
- \\
+ \\
+ \\
-\end{array}$ & $\begin{array}{l}+ \\
+ \\
+ \\
+ \\
+ \\
- \\
+ \\
+ \\
+\end{array}$ & $\begin{array}{l}+ \\
+ \\
+ \\
+ \\
+ \\
+ \\
+ \\
+ \\
+\end{array}$ & $\begin{array}{l}+ \\
+ \\
+ \\
+ \\
+ \\
- \\
+ \\
+ \\
+\end{array}$ & $\begin{array}{l}+ \\
+ \\
- \\
+ \\
+ \\
+ \\
+ \\
+ \\
+\end{array}$ & $\begin{array}{l}+ \\
+ \\
+ \\
+ \\
+ \\
+ \\
+ \\
- \\
\text { FALEC } \\
\text { G/1/72 }\end{array}$ & $\begin{array}{l}+ \\
+ \\
- \\
+ \\
+ \\
+ \\
+ \\
-\end{array}$ & & \\
\hline 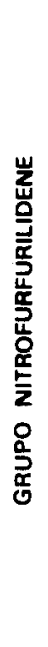 & $\begin{array}{l}\text { A.B.D. } \\
\text { A.A. } \\
\text { A.A.Z. } \\
\text { C.R. } \\
\text { C.B. } \\
\text { B.P.S. } \\
\text { C.A.F. } \\
\text { E.A. } \\
\text { F.S. } \\
\text { A.T.S. } \\
\text { G.R.V. } \\
\text { H.R. } \\
\text { J.R.P. } \\
\text { J.L.Q. } \\
\text { J.A.S. }\end{array}$ & $\begin{array}{l}+ \\
+ \\
+ \\
+ \\
+ \\
+ \\
+ \\
+ \\
+ \\
+ \\
+ \\
+ \\
+ \\
+ \\
+\end{array}$ & $\begin{array}{l}+ \\
+ \\
+ \\
+ \\
+ \\
- \\
+ \\
+ \\
+ \\
- \\
+ \\
+ \\
+ \\
+ \\
+\end{array}$ & $\begin{array}{l}+ \\
+ \\
+ \\
+ \\
+ \\
+ \\
+ \\
+ \\
+ \\
+ \\
+ \\
+ \\
+ \\
+ \\
+\end{array}$ & $\begin{array}{l}+ \\
+ \\
+ \\
+ \\
+ \\
- \\
+ \\
- \\
+ \\
- \\
+ \\
+ \\
+ \\
+ \\
-\end{array}$ & $\begin{array}{l}- \\
- \\
- \\
- \\
- \\
- \\
- \\
- \\
- \\
- \\
- \\
- \\
- \\
+\end{array}$ & $\begin{array}{l}- \\
- \\
- \\
- \\
- \\
- \\
- \\
- \\
- \\
- \\
- \\
- \\
-\end{array}$ & $\begin{array}{l}- \\
- \\
- \\
- \\
- \\
- \\
- \\
- \\
- \\
- \\
- \\
- \\
- \\
-\end{array}$ & $\begin{array}{l}- \\
- \\
- \\
- \\
- \\
- \\
- \\
- \\
- \\
- \\
- \\
- \\
-\end{array}$ & $\begin{array}{l}- \\
- \\
- \\
- \\
- \\
- \\
- \\
- \\
- \\
- \\
- \\
- \\
-\end{array}$ & $\begin{array}{l}- \\
- \\
- \\
- \\
- \\
- \\
- \\
- \\
- \\
- \\
- \\
- \\
- \\
- \\
-\end{array}$ & $\begin{array}{l}- \\
- \\
- \\
- \\
- \\
- \\
- \\
- \\
- \\
- \\
- \\
- \\
- \\
-\end{array}$ & $\begin{array}{l}- \\
- \\
- \\
- \\
- \\
- \\
- \\
- \\
- \\
- \\
- \\
- \\
-\end{array}$ & $\begin{array}{l}- \\
- \\
- \\
- \\
- \\
- \\
- \\
- \\
- \\
- \\
- \\
- \\
- \\
-\end{array}$ & $\begin{array}{l}- \\
- \\
- \\
- \\
- \\
- \\
- \\
- \\
- \\
\text { FALE } \\
- \\
- \\
- \\
-\end{array}$ & $\begin{array}{l}- \\
- \\
- \\
- \\
- \\
- \\
- \\
- \\
- \\
- \\
- \\
- \\
- \\
-\end{array}$ & $\begin{array}{l}- \\
- \\
- \\
- \\
- \\
- \\
- \\
- \\
- \\
16 / 71 \\
- \\
- \\
- \\
- \\
-\end{array}$ & $\begin{array}{l}- \\
- \\
- \\
- \\
- \\
- \\
- \\
-\end{array}$ & $\begin{array}{l}- \\
- \\
- \\
- \\
- \\
- \\
- \\
-\end{array}$ & $\begin{array}{l}- \\
- \\
- \\
- \\
- \\
- \\
- \\
-\end{array}$ & $\begin{array}{l}- \\
- \\
- \\
- \\
- \\
- \\
- \\
-\end{array}$ & $\begin{array}{l}- \\
- \\
- \\
- \\
- \\
- \\
- \\
-\end{array}$ & $\begin{array}{l}\text { FALE } \\
\text { ALTA }\end{array}$ & $\begin{array}{l}- \\
- \\
-\end{array}$ \\
\hline
\end{tabular}


chagásica. Quanto aos testes laboratoriais, não acusaram nenhuma modificação das funções hepáticas, hematopolética e renal.

No que diz respeito às alterações ponderais tivemos oportunidade de referir quando abordamos os efeitos colaterais.

\section{COMENTÁRIOS}

Na fase crônica da Moléstia de Chagas, são inexpressivos os sintomas e sinais clínicos de infecção. Quanto aos demais que forem cb;ervadcs, devem ser relacionadas às afecções resultantes e, por conseguinte, não se pode esperar alterações neles $\mathrm{em}$ conseqüência do tratamento específico.

Mesmo na sua forma aguda, o quadro clínico tem muito pouco valor na avaliação da eficácia de lima terapêutica etiolózica, pois na maioria dos casos os sintomas regridem espontaneamente, dentro de semanas ou meses ainda que na ausênc a de qualquer tratamento.

Uma análise dos trabalhos de Cerisola et alii ( 7 e 8), Tourres (18) e Rassi \& Ferreira (15) mostra que nas provas sorológicas os casos agudos tratados com esquemas adequados de Nitrofurfurilidene negativam em corca de $80 \%$. Quanto à fase crônica da infecção chagásica, o único trabalho que apresenta um estudo sorológico bem conduzido é o de Schenone et alii (17), os quais, usando a Reação de Fixação do Complemento e a Reação de Hemoaglutinação, verif:caram que tais provas permaneciam positivas após 10 meses da conclusão do tratamento, notando somente uma diminuição do título. Os resultados da sorologia dos nossos pacientes concordam com os referidos acima, isto é, todos os soros - após 4 anos do término do tratamento - ainda se mostram reagentes, embora se observe uma queda nos títulos, tanto na Reação de Imunofluorescência como na Reação de Hemoaglutinação. Schenone et alii (17) fazem o seguinte comentário a propósito de tal observação: "La persistencia de anticuerpos inmunodiagnósticos (RCF y RHA positivas) conjuntamente con la ausencia aparente del antígeno representado por el $T$. cruzi, perm 't'ria suponer que estamos en presencia de una situación similar a la que ocurre en sífilis $y$ otras infecciones crónicas tales como el pian o frambesia. en las cuales la serologia permanece positiva después de um tratami- ento considerado adecuado (Medina, 1959)" e terminam afirmando que "La serología no constituiría un criterio adecuado para evaluar la efectividad de un tratamiento en la infección chagásica crônica." Com o que não concordam Cançado et alii (6) quando, após uma série de ponderáveis argumentos, concluern: "Embora não se tenha ainda estabelecido o critério de cura da doença de Chagas, é de crer-se que, curada a doença, o xenodiagnóstico e as reações sorológicas deverão negativar-se."

De tudo isso, o que resta de real e de efetivamente intrigante é o desencontro entre os achados do xenodiagnóstico e os das provas sorológicas.

A extinção definitiva, pelo menos em aparência, da parasitemia sugeriria o estabelecimento de uma "sterilisatia magna", isto é, a total eliminação do parasita. Mas tal conclusão contrastaria com a generalizada positividade das provas sorológicas, permanecendo por um período tão prolongado.

A outra suposição cabível e talvez mais válida é a de que o parasita, num novo estado de equilíbrio com o hospedeiro, ainda permaneça sob formas amastigotas em número reduzido, condicionando pa:sagens tão discretas para a forma hemocirculante que se tornaria indetectável pelo xenodiagnóstico, prova esta de sensibilidade sabidamente baixa $(58 \%$ segundo nossa experiência, obtida por método semelhante $\mathrm{e}$ não menos sensivel que o preconizado por Schenone et alii (17)).

\section{PRINCIPAIS CONSTATAÇÓES}

1 - Com o nitrofurfurilidone administrado a 15 pacientes na fase crônica da infecção chagásica, na dose diária de 8-10 miligramas por quilo de pêso, durante 120 dias obteve-se a negativação da prova de xenodiagnóstico, em $100 \%$ dos casos.

2 - Em toulos eles, a parasitemia estava desaparecida aos 60 dias de tratamento e ainda se mantinha ausente 4 anos após, prazo esse que não deixa de ser significativo.

3 - Os examos sorológicos quantitativos revelaram que todos os soros ainda se mostram reagentes, observando-se, porém, um declínic dos anticorpos nos pacientes tratados, em comparação com o grupo placebo. 


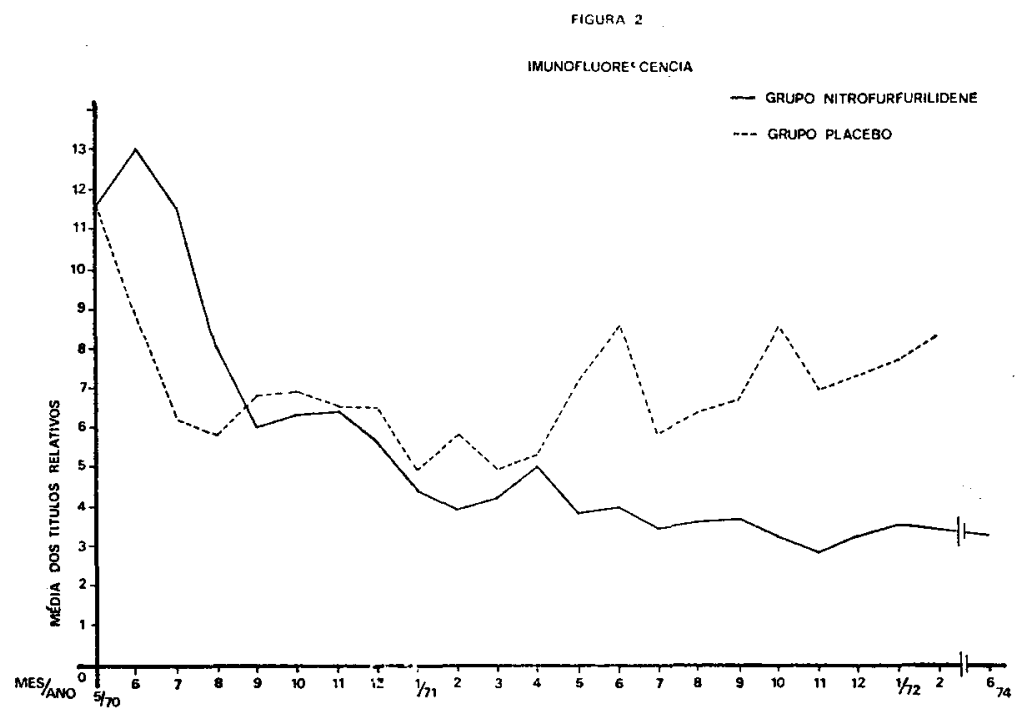

FIGURA 2 - Curva da média dos títulos relativos dos anticorpos tmunofluorescentes.

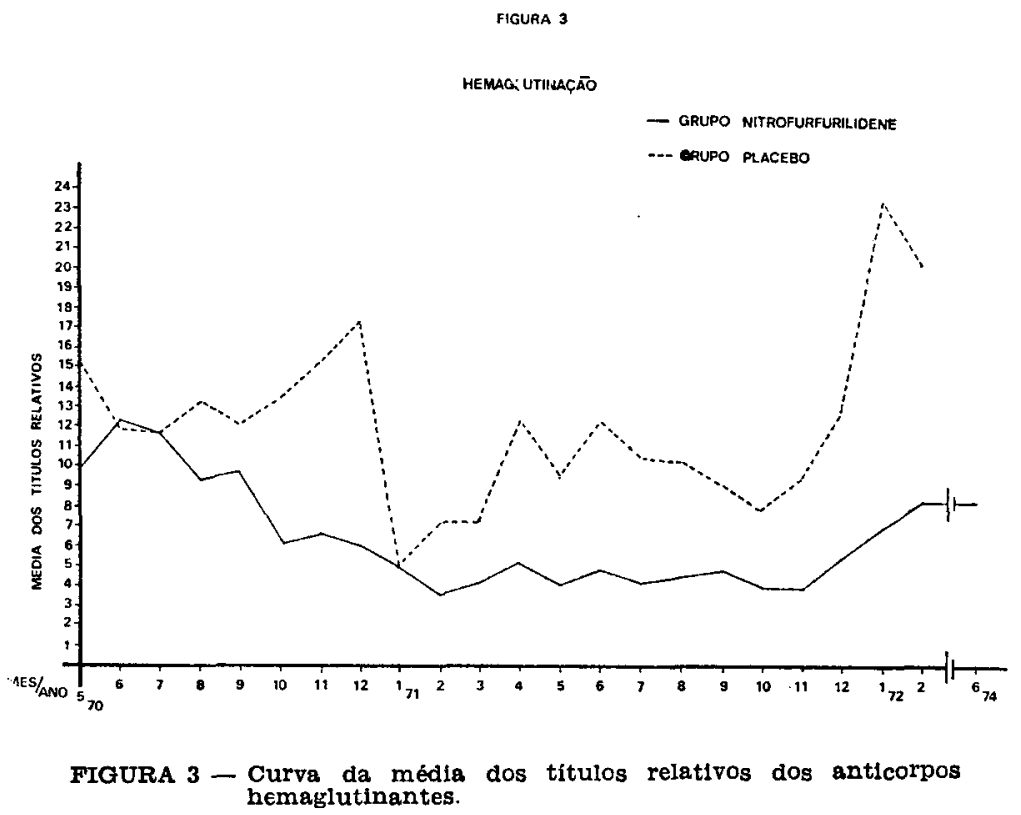


4 -- Os efeitos colaterais, que se mostraram reversiveis quando da interrupção do tratamento, mais presentes foram:

- perda de peso, hiporexia, má tolerância digestiva (náuseas e/ou vômitos), salientando-se entre as alterações neurológicas miastenia de membros inferiores e parestesia, cumprindo-nos ainda destacar um caso severo de eritrodermia exfoliativa.

Notamos que, o aparecimento dos para-efeitos neurológicos guardam relação direta com o tempo de ministração da droga.

5 - Em virtude da negativação dos xenodiagnó:ticos após 6 J dias de terapêutica e pelo fato dos efeitos colaterais mais graves (neurológicos) terem se manifestado em torno do $90^{\circ}$ dia está indicada uma nova pesquisa por um periodo mais curto de tratamento (45-60 dias) ${ }^{* *}$ com a finalidade de determinar o tempo ideal de ministração da droga.

\section{CONCLUSŌES}

1 - Persistência da pasitividade das provas sorológicas ao lado da persistência da negatividade do xenodiagnóstico por um periodo de 4 anos após o início do tratamento, trouxe-nos certa dificuldade na avaliação definitiva da eficácia do $\mathrm{Nt}$ trofurfurilidene na fase crônica da infecção chagásica, pois em termos de ausência de parasitas a droga seria altamente eficaz, porém, em termos de presença de anticorpos os resultados não seriam tão brilhantes.

2 - A ação do Nitrofurfurilidene, inquestionavelmente plena na forma aguda da infecção e aparentemente parcial na forma crônica, deixa fora de dúvida seu caráter específico. Isso basta para recomendar a realização de novas pesquisas. Primeiro para esclarecer definitivamente os resultados do tratamento nas formas crônicas, segundo, para, no caso de êxitos parciais, se poder partir para novas manuseios com a droga até que se obtenham resultados tão satisfatórios quanto os que se verificam na forma aguda.

\section{AGRADECIMENTOS}

Agradecemos ao corpo técnico do Instituto de Diagnóstico e Investigacion de la Enfermedad de Chagas "Dr. Mário Fatala Chaben" de Buenos Aires e à Bayer pela ajuda proporcionada para a realização do presente trabalho.

\section{$S U M M A R Y$}

Twenty five patients with chronic Chagas' disease were selected presenting positive serology and high parasitaemia. A group of fifteen partients was treated with Nitrofurfurilidene during 120 days with daily doses of 8-10 $\mathrm{mg}$ per $\mathrm{kg}$ of body weight. The remaining group of ten individuals received only placebo.

Yatrogenis alteration of liver, hematopoiesis or kidney were not observed during or after treatment.

Xenodiăgnosis of the experimental 15 patient group was negative at the $60 t$ day of treatment and remained so up to 5 years that the observation lasted.

Iiegarding the serum diagnosis the behaviour was not alike eventhough the experimental group presented lower levels of antibodies after the 12th month of the treatment.

The authors discuss the disagreement between the xenodiagnosis and serologis results and offer an hypothesis to justify it. They conclude that Nitrofurfurilidene has some efficiency in the chronic phase of Chagas' disease although less evident than in the acute form.

\footnotetext{
* Tal ensaio, contando com a mesma equipe de trabalho, acha-se em fase de conclusâo.
} 


\section{EXPERIENCIAS BIBLIOGRÁFICAS}

1 - BOCK, M., CÖNNERT, R. \& HABERKORN, A. - Studies with Bay 2502 on animals. Bol. Chil. Parasit 24: 13-19, 1969.

2 - BOYDEN, S. V. - The absorption of protein on erytrocytes treated with tannic acid and subsquent hemaglutination by anti-proteinsera. J. Exp. Med. 93: 107-120, 1951 .

3 - BRANT, T.C., LARANJA, F.S., BUSTAMANTE, F.M. \& MELO, A.L. Dados sorológicos e eletrocardiográficos obtidos em população não selecionada de zonas endêmicas de Doencas de Chagas no Estado do Rio Grande do Sul. R. Bras. Mal. Doe. Trop. 9: 141-148, 1957.

4 - BRENER, Z. - Atividade terapôtica do 5 - nitro-furaldeido-semi-carbazona (nitrofurazona) em esquemas de duração prolongada na infeccão exporimental do camundongo pelo Trypanosoma cruzi. Rov. Inst. Med. Trop. São Paulo, 3: 43-49, 1961.

5 - CAMARGo, M.E. - Fluorescent antihodv test for the sarodiamnncis of American Trypanosomiasis. Technical modification empolving preserved cilture forms if Trupanosoma cruzi in a slide test. Rov. Tnst. Med. Trop. Sāo Paulo, 8: 227-234, 1966.

6 - Cantano, J.R., MarRa, TT $n$., MOTTRAO O.G.. ATIVARTS. J.M., OLTVF:TRA. T.P.M., MACHADO, J.R. \& SAT.SADO, A.A. - Bases nora a.valiacão do tratamento ernecifico da Hoença de Chaơas Hrimana sppindo $\rightarrow$ parasitemia. Rav. Soc. Bras. Med. Trop. 7: 155-166, 1973.

7 CERTGOTA. J.A., AT.VARFG. M. \& DF, RAGST. A.M. - Imunndiagnósticn da Noonça de Chaoras. Rev. Tnet. Mar. Trop. São Paulo, 12: 403-411, 1970.

8 - CFRTSOTA, J.A. \& LAZZART. J. Resultiados obtenidos con el toct hemaglutinacion para, el diagnóstico d? la enfermidad de Chagas. Proc. VII Inter Congr. Trop. Med. Malar. 2: 252-253, 1963.

9 - CERTSOLA, J.A. \& ROSENBAUM, M.B. - La reacion de fijacion del complemento para el diagnóstico de la enfermidad de Chagas. Prensa Med. Argent., 45: 1454-1463, 1968.
10 - COURA, J.R. \& SILVA, J.R. - Aspectos atuais do tratamento da Doenca de Chagas. Arq. Bras. Med., 51: 283-290, 1961.

11 - FERREIRA, H.O., PRATA, A. \& RASSI, A. - Administração prolongada de nitrofurazona no tratamento da Doença de Chagas aguda. Hospital, 63: 1391-1396, 1963.

12 - LIMA, D.F., SILVA, N.N., SAN̂TOS, J.F.C., ZINGANO, A.G., FROES, O.M. \& C.AAER, J.A.B. - Resultado parcial do xenodiagnóstico realizado em um grupo de pacientes serologicamente positivos para a Doença de Chagas e internados no Hospital São Pedro (de alienados) em Porto Alegre, Rio Grande do Sul, Brasil. Rev. Soc. Bras. Med. Trop. 4: $367-370,1970$

13 - MARRA, U.D. - Ensáio terapêutico clínico com a Nitrofurazona e a Levofuraltadona na forma crônica da Doença de Chagas. Tese, Belo Horizonte, Imprensa da Univ. de Nilas Gerais, publ. no 350,1965 , cap. I, pp. 1726 .

14 - RASSI, A. - Atualização terapêutica da Doença de Chagas e critério de avaliação de cura. J. Bras. Med., 10: 531-535, 1966.

15 - RASSI, A. - \& FERREIRA, HO. Tentativas de tratamento específico da fase aguda da Doença de Chagas com nitrofuranos em esquemas de duração prolongada. Rev. Soc. Bras. Med. Trop. 5: 149-262, 1971.

16 - SCHENONE H., ALFARO. E., BEYES, H. \& TAUCHER, E. - Valor del Xenodiagnóstico en la infeccion chagasica crônica. Bol. Chil. Parasit., 23: 149-154, 1968 .

17 - SCHFNONE. H., CONCHA. I. . ARANDA, R., ROTAS, A. \& ALFARO. E. - Exneriência terapêutica con el BAY 2502 en la infeccion chagasica crenica del adulto. Imbortancia del 110 adocuado del xonoriamnótico. Bol. Chil. Parasit., 24: 66-69, 1969.

18 - TOUJRES C.L.B. - L enfermidad de Chagas en perioto aoudo $y$ su tratamiento con el BAY 2502, Bol. Chil. Parasit. 24: 24-27, 1969. 